\title{
DA PUREZA METODOLÓGICA À DIFERENCIAÇÃO FUNCIONAL DOS SISTEMAS SOCIAIS. É POSSÍVEL UM FUNDAMENTO MORAL DA ORDEM JURÍDICA?
}

FROM METHODOLOGICAL PURITY TO THE FUNCTIONAL DIFFERENTIATION OF SOCIAL SYSTEMS. IS A MORAL FOUNDATION OF THE LEGAL ORDER POSSIBLE?

DE LA PUREZA METODOLÓGICA A LA DIFERENCIA FUNCIONAL DE LOS SISTEMAS SOCIALES. ¿ES POSIBLE UN FUNDAMENTO MORAL DEL ORDEN JURÍDICO?

Licença CC BY:

Artigo distribuído sob os termos Creative Commons, permite uso e distribuição irrestrita em qualquer meio desde que o autor credite a fonte original.
Paulo Roberto Ramos Alves ${ }^{1}$

\section{Fabíola Wüst Zibetti²}

Resumo: Os sistemas sociais operam em condições de clausura operativa, negando a possibilidade de validade direta da moral no interior do sistema jurídico. Da especificação do sistema como unidade, o Direito apenas é válido como Direito, bem como a moral apenas é válida como moral. Em outras palavras, o fechamento operativo do sistema jurídico não permite que a moral delimite diretamente o conteúdo do Direito, muito embora sejam possíveis formas específicas de inter-relações entre esses dois âmbitos comunicativos, bem como a assimilação jurídica da comunicação moral. Nessa ótica, a importância da moral ou sua utilização pelo Direito não é relegada a um plano de menor importância, mas questiona simplesmente a busca de um fundamento moral para o sistema jurídico, salientando que a tese do fechamento operativo dos sistemas autopoiéticos assume justamente uma posição contrária à possibilidade de validade imediata da moral autônoma no campo do Direito.

Palavras-chave: Autopoiese; Direito; Moral; Teoria dos Sistemas.

$1 \quad$ Doutor em Direito pela Universidade do Vale do Rio dos Sinos (UNISINOS), com Estágio Pós-Doutoral pela Universidade de Passo Fundo (UPF); Professor na Universidade de Passo Fundo (UPF) e na Universidade do Oeste de Santa Catarina (UNOESC); Advogado; E-mail: pauloalvess@yahoo.com.br

2 Doutora em Direito Internacional, pela Faculdade de Direito da Universidade de São Paulo (USP), com Pós-Doutorado pelo Programa da Pós-Graduação em Direito da Universidade Federal de Santa Catarina (UFSC) e pelo Centro Ibero-Americano, vinculado ao Instituto de Relações Internacionais da USP. E-mail: pauloalvess@yahoo.com.br. 
Abstract: Social systems operate in conditions of operational closure denying the possibility of direct validity of morals within the legal system. From the specification of the system as a unit, the Law is only valid as Law, and morality is only valid as a moral. In other words, the operative closure of the legal system does not allow morality to directly delimit the content of law, although specific forms of interrelation between these two communicative spheres are possible, as well as the legal assimilation of moral communication. From this perspective, the importance of morality, or its use by law, is not relegated to a less important level, but simply puts into question the search for a moral foundation for the legal system, emphasizing that the thesis of the operational closure of autopoietic systems assumes a contrary position to the possibility of immediate validity of autonomous morality in the field of law.

Keywords: Autopoiesis; Law; Moral; Theory of Systems.

Resumen: Los sistemas sociales operan en condiciones de clausura operativa, negando la posibilidad de validad directa de la moral en el interior del sistema jurídico. De la especificación del sistema como unidad, el Derecho apenas es válido como Derecho, bien como la moral apenas es válida como moral. En otras palabras, el cierre operativo del sistema jurídico no permite que la moral delimite directamente el contenido del Derecho, aunque sean posibles formas específicas de interrelaciones entre estos dos ámbitos comunicativos, bien como la asimilación jurídica de la comunicación moral. En esta óptica, la importancia de la moral o su utilización por el Derecho no es relegada a un plano de menor importancia, pero cuestiona simplemente la búsqueda de un fundamento moral para el sistema jurídico, subrayando que la tesis del cierre operativo de los sistemas autopoiéticos asume justamente una posición contraria a la posibilidad de validez inmediata de la moral autónoma en el campo del Derecho.

Palabras-clave: Autopoiesis; Derecho; Moral; Teoría de los Sistemas.

\section{INTRODUÇÃO}

Desde a escola conceitualista, o direito encontra nítidos problemas relacionados com a interpretação jurídica, que por vezes buscou uma fundamentação de ordem moral para a ordem jurídica, o que refletiu no processo decisório dos tribunais. A notória insuficiência de um sistema jurídico conceitual fechado apontou para construções que marcaram profundamente a práxis jurídica. Com o Movimento do Direito Livre, a subjetividade do intérprete passou a eivar o processo de interpretação, permitindo o ingresso de elementos volitivos, psicológicos e moralizantes no âmbito interno do direito.

Nesse contexto, várias observações da ordem jurídica foram construídas, buscando explicar o papel da moral no direito. De Kelsen a Luhmann, passando por Hart e Radbruch, o problema da relação entre direito e moral foi enfrentado 
sob diferentes perspectivas, as quais afirmaram diferentes e importantes óticas que o presente texto busca analisar.

Amparado no método sistêmico, o texto ora apresentado direciona seus esforços à observação da funcionalidade do sistema jurídico a partir de uma perspectiva autopoiética, a qual permite a observação da esfera da moralidade a partir da distinção binária que caracteriza o sistema jurídico, qual seja, direito/ não-direito. Nesse passo, serão observadas diferentes perspectivas teóricas até se alcançar a análise do direito como sistema autopoiético e, via de consequência, avaliando a relação entre direito e moral.

\section{A PUREZA METODOLÓGICA KELSENIANA}

Na primeira metade do século XX, Hans Kelsen delimita o direito como objeto de estudo da ciência jurídica, distinguindo-o, portanto, das ciências naturais. Com essa distinção, passa a reconhecer a existência de outras normas destinadas à regulação das relações entre os homens, evidenciando que o direito não é a única espécie de norma social existente. Além do direito, Kelsen reconhece a existência de normas morais, sobressaindo a ética como o ramo das ciências que se ocuparia com o estudo e a descrição da moral. ${ }^{3}$

Diante do reconhecimento de que a ética se ocupa da justiça, Kelsen estabelece que a discussão da relação entre moral e direito necessariamente contém a questão da justiça implícita e atenta para o fato de que comumente a moral é confundida com a ética, assim como ocorre com a distinção entre direito e ciência jurídica. Isso conduz a um grave problema de ordem metodológica e culmina na impossibilidade de se distinguir direito e moral.

O caráter social das normas morais, por sua vez, é colocado em cheque pela afirmação de que existem normas morais que prescrevem condutas unicamente interiores ao homem. Todavia, o alcance social dessas normas é reafirmado pelo autor austríaco, quando reconhece que, mesmo aquele preceito moral que imediatamente delimita uma conduta interior, mediatamente atinge toda a coletividade, ingressando na consciência coletiva na forma de uma norma moral. ${ }^{4}$

$3 \quad$ KELSEN, Hans. Teoria pura do direito. 7. ed. São Paulo: Martins Fontes, 2006. p. 67.

4 KELSEN, Hans. Teoria pura do direito. 7. ed. São Paulo: Martins Fontes, 2006. p. 68-70. 
A questão interioridade/exterioridade da moral e do direito é criticada por Kelsen, eis que, para o autor, tanto as normas morais como as normas jurídicas regulamentam tanto estados internos quanto internos. ${ }^{5} \mathrm{Em}$ outras palavras, condutas interiores são condicionadas por condutas exteriores, bem como o contrário é igualmente válido, eis que condutas exteriores são igualmente condicionadas por condutas interiores. Contudo, Kelsen reconhece que a distinção entre moral e direito apenas pode ser realizada se se partir do fato de que a moral se destina primariamente à regulamentação de uma conduta interior, ao passo que o direito dispõe tanto sobre a conduta interna quanto a externa.

A distinção entre direito e moral igualmente não pode ser realizada a partir da produção ou da aplicação de suas normas. Para Kelsen, a moral é igualmente uma criação social, sendo, portanto, igualmente positiva. Logo, a distinção entre direito e moral não pode fundar-se no objeto de prescrição (moral e jurídica), mas sim na forma sob a qual ambas as ordens prescrevem ou proíbem determinadas condutas. ${ }^{6}$

Dessa maneira, afigura-se como central para Kelsen a questão da sanção. 0 direito apenas pode ser compreendido como direito a partir da ideia de coerção, ou seja, da sanção pela violação de determinado preceito legal. Já a moral não possui vinculação à coerção, sendo que, no caso de violação de preceitos morais, apenas se pode falar em aprovação/desaprovação, sem haver qualquer possibilidade de emprego da força como forma de assegurar a manutenção de uma norma de conteúdo moral. ${ }^{7}$

O direito, entretanto, possui valor no domínio da moral. Isso significa que o direito é uma parte constitutiva da ordem moral, logo, a análise kelseniana considera o direito como integrante da moral, identificando-se, assim, direito e justiça. O caráter de normas sociais é o elemento comum a todos os sistemas morais. Em outras palavras, não é o conteúdo, mas a forma do elemento comum aos sistemas morais. A partir dessa afirmação, o entendimento de Kelsen de que o direito é essencialmente moral não decorre de um pretenso conteúdo moral em si mesmo considerado, mas sim ao fato de que o jurídico é norma (social) e, por isso, estabelece determinada conduta humana. ${ }^{8}$

$5 \quad$ KELSEN, Hans. Teoria pura do direito. 7. ed. São Paulo: Martins Fontes, 2006. p. 68-70.

6 KELSEN, Hans. Teoria pura do direito. 7. ed. São Paulo: Martins Fontes, 2006. p. 71.

7 KELSEN, Hans. Teoria pura do direito. 7. ed. São Paulo: Martins Fontes, 2006. p. 71.

8 KELSEN, Hans. Teoria pura do direito. 7. ed. São Paulo: Martins Fontes, 2006. p. 74. 
Sob tal afirmação, é possível entender que todo o direito possui um valor moral relativo. Todavia, é de ser reafirmado que esse entendimento se sustenta não no conteúdo do direito e das normas morais, mas sim quanto à sua forma. A validade de uma ordem jurídica não depende de uma vinculação prévia e fundamental a determinado sistema moral absoluto, ou, ainda, de sua concordância ou discordância para esse sistema. ${ }^{9}$

O direito, então, é valorativo tão somente pelo fato de ser norma, ou seja, o valor jurídico é constituído justamente por esse fato, caracterizando-se igualmente como um valor moral relativo. Essa relatividade do valor das normas morais para o direito é evidenciada pelo fato de que qualquer valoração moral do direito será relativa frente a outros sistemas morais.

Em outras palavras, qualquer valoração boa ou má apenas é possível frente a determinado sistema moral, não sendo excluídas outras valorações a serem realizadas por outros sistemas da moral. Dessa maneira, Kelsen rechaça a existência de uma moral absoluta, reconhecendo, do ponto de vista da ciência do direito, sob o qual é assentado sua pureza metodológica, que inexiste a moral, mas sim vários sistemas morais diversos.

\section{A EQUIDADE EM HART}

Por sua vez, Herbert Hart se ocupa da problemática das relações entre direito e moral a partir da ideia de equidade. Essa construção decorre de uma dupla questão: primeiro, a distinção, na esfera geral da moral, da ideia de justiça e sua conexão com o direito. Em segundo lugar, em relação às características que diferenciam as regras, os princípios morais, de todas as outras formas de regras sociais ou padrões de conduta. ${ }^{10}$

A ideia de justiça em Hart tem a ver fundamentalmente com a equidade. Nesses termos, a justiça diz respeito ao direito que os indivíduos possuem, uns em relação aos outros, ao estabelecimento de determinado grau de igualdade ou de desigualdade. A igualdade, portanto, deve ser algo caro ao direito, devendo ser observada quando da distribuição de encargos ou benefícios. A Dessa maneira,

9 KELSEN, Hans. Teoria pura do direito. 7. ed. São Paulo: Martins Fontes, 2006. p. 75-76.

10 HART, Herbert L. A. O conceito de direito. Lisboa: Fundação Calouste Gulbenkian, 1994. p. 171. 
a justiça deve ser observada como um elemento capaz de manter um equilíbrio ou proporção. ${ }^{11}$

O problema colocado por Hart no que tange à valoração do justo diz respeito às fundamentais diferenças entre os seres humanos. O estabelecimento daquilo tido como justo mediante a simples distinção entre semelhanças e diferenças mostra-se problemático, tornando-se necessário considerar quais semelhanças e quais diferenças serão relevantes para se observar determinada disposição como justa ou injusta. Com base nessa necessidade, Hart entende que a ideia de justiça é complexa, consistindo em duas partes, ou seja, em um aspecto constante que deriva da obrigação de tratar de forma semelhante os casos semelhantes, bem como por um aspecto mutável, utilizável para delimitar quais são os casos semelhantes. ${ }^{12}$

Hart chama a atenção para a impossibilidade de mudanças sociais que estejam em harmonia com todos os indivíduos. Nesse contexto, a junção entre justiça e bem social perpassa pela consideração dessa diferença, eis que apenas leis que assegurem necessidades tidas como elementares são capazes de se aproximarem dessa ligação entre direito e justiça.

A justiça caracteriza-se como um elemento da moral que se ocupa com os modos como são tratadas classes de indivíduos. A justiça, contudo, não esgota a esfera da moral, tornando-se necessária a caracterização dos padrões de comportamentos então pertencentes à esfera da moralidade. Para Hart, é um equívoco identificar a justiça com a conformidade ao direito, eis que as próprias leis podem ser classificadas como justas ou injustas. Para tanto, o autor diferencia quatro características básicas de padrões de comportamento morais nomeando-os critérios formais -, buscando, com isso, ultrapassar a mera diferença interioridade/exterioridade e aprofundar a distinção entre direito e moral.

A primeira distinção diz respeito à importância. As normas morais afirmamse frente às paixões e aos impulsos humanos, limitando o exercício desses sentimentos, de modo a possibilitar o reconhecimento e a utilidade de sua aceitação. As normas morais apenas subsistem enquanto sua importância é 
saliente. Contrariamente às normas jurídicas, as normas morais não dependem de revogação (como as normas jurídicas) quando não mais interessam à sociedade, sendo o critério de importância condição para a manutenção das normas morais. ${ }^{13}$

O segundo elemento proposto por Hart refere-se à imunidade à alteração deliberada. Contrariamente ao que ocorre com as normas jurídicas, as normas morais não são passíveis de alteração por meio de um ato deliberado. Nesse aspecto, Hart afirma que a moral apenas é possível quando adquire o status de tradição, sendo isso possível apenas pelo seu desenvolvimento, prática e desuso no meio social, independentemente de uma força reguladora. ${ }^{14}$

Em terceiro lugar, Hart afirma o caráter voluntário dos direitos morais, sendo que a intenção é fator fundamental para a responsabilização de ordem moral. A distinção entre a responsabilização moral e jurídica é saliente nesse aspecto, eis que o caráter volitivo é central para a delimitação da responsabilização moral, enquanto na esfera jurídica a intencionalidade não é requisito para eventual responsabilização. ${ }^{15}$

Por último, Hart observa a forma de pressão moral. As normas morais sustentam-se em si próprias para sua imposição. O respeito à norma moral é algo tido como pressuposto por todos os destinatários da norma, sendo que a sanção moral equivaleria a um sentimento de vergonha ou de culpa a ser suportado pelo transgressor. Não há, no âmbito moral, sanções objetivas como as características das normas jurídicas, por isso a forma de pressão exercida pela moral caracterizase justamente por uma pretensa tradição, na qual toda a coletividade (em tese) resta comprometida com determinados elementos tidos como centrais para o bem comum e para seu regular desenvolvimento. ${ }^{16}$

\section{A MORAL COMO FIM DO DIREITO EM RADBRUCH}

Diferentemente de Hart, porém da mesma forma que Kelsen, Gustav Radbruch traça a delimitação entre os campos da moral, da ética, da justiça e do direito, afirmando que similitude entre tais esferas apenas poderá existir quando

13 HART, Herbert L. A. O conceito de direito. Lisboa: Fundação Calouste Gulbenkian, 1994. p. $188-189$.

14 HART, Herbert L. A. O conceito de direito. Lisboa: Fundação Calouste Gulbenkian, 1994. p. $190-191$.

15 HART, Herbert L. A. O conceito de direito. Lisboa: Fundação Calouste Gulbenkian, 1994. p. 193.

16 HART, Herbert L. A. O conceito de direito. Lisboa: Fundação Calouste Gulbenkian, 1994. p. 195. 
confrontados justiça vs. ética e direito vs. moral. A partir dessa delimitação, o autor observa a diferença interioridade/exterioridade em relação à discussão direito e moral. Nesse contexto, direito e ética apresentam-se como dois campos de naturezas diversas, sendo o direito um conceito cultural, enquanto a ética é caracterizada como um conceito valorativo. ${ }^{17}$

A distinção interioridade/exterioridade do direito e da moral é criticada por Radbruch, sob o entendimento de que, por vezes, a valoração jurídica não se limita à conduta exterior, bem como de que a valoração moral não é sempre limitada a incidir sobre a conduta interior. Nesse passo, o autor igualmente entende que a moral não pode ser relacionada à mera intenção (seja boa ou má), mas sim à ação, eis que somente pela ação a moral demonstra sua existência. É forçoso o reconhecimento de que tanto a conduta exterior pode ser valorada moralmente, como a conduta interior pode ser valorada juridicamente. Por isso, a conduta exterior apenas adquire relevância para a moral quando exprime uma conduta interior, bem como a conduta interior somente é de interesse jurídico quando anuncia uma conduta exterior. ${ }^{18}$

Por sua vez, o valor atribuído pelo direito diz respeito às ações como boas (e necessárias) para a vida em comum, enquanto o valor moral refere-se àquilo que é bom em si mesmo. O valor moral refere-se, portanto, ao valor da própria ação, enquanto o valor jurídico é o valor que a ação tem para os outros. Quando se fala em direito, se reconhece a existência de direitos e obrigações. A moral, por sua vez, refere-se simplesmente à existência de um dever, não sendo possível a exigência de cumprimento de um dever moral. ${ }^{19}$

Já a oposição entre interioridade/exterioridade em relação ao modo como as normas morais e jurídicas obrigam, aponta para o fato de que a moral exige o cumprimento dos deveres pelo sentimento de dever, sendo o dever moral seu próprio fim. Já o cumprimento do dever jurídico pressupõe uma finalidade, sendo necessário o emprego de uma conduta que esteja de acordo com o preceito jurídico. Além do mais, a moral apenas pode ter como objeto o homem individual, enquanto o direito direciona-se à vida dos homens em comum, onde 17 RADBRUCH, Gustav. Filosofia do direito. Coimbra: Armênio Amado Editor, 1974. p. 98.

18 RADBRUCH, Gustav. Filosofia do direito. Coimbra: Armênio Amado Editor, 1974. p. 99-100.

19 RADBRUCH, Gustav. Filosofia do direito. Coimbra: Armênio Amado Editor, 1974. p. 101.102. 
diretamente apenas a conduta exterior interessa. ${ }^{20}$

Radbruch observa que direito e moral apenas coincidem quanto ao conteúdo de suas exigências, relacionando-se no sentido de que a moral apresentase, por um lado, como o fim do direito e, por outro, como o fundamento da validade jurídica. A força obrigatória do direito somente pode decorrer da moral. Contudo, a moral como fundamento da obrigatoriedade jurídica não aponta para a impossibilidade de separação entre as duas ordens normativas, eis que a moral, ao legitimar as operações jurídicas, "pondo no direito e na justiça o selo que os há de transformar em uma atividade moral"21, abandona essas mesmas operações para que seu conteúdo seja determinado por um conjunto normativo diverso do seu e, portanto, extramoral.

Logo, para Radbruch, o direito serve a moral em função dos direitos que ele outorga. Em outras palavras - na esteira dos pressupostos da autonomia kantiana ${ }^{22}$-, o direito se volta para moral no momento em que assegura direitos aos indivíduos, possibilitando que esses indivíduos possam melhor cumprir seus deveres. Nesse sentido, o direito que alguém possui é, fundamentalmente, o direito ao cumprimento de um dever moral, o que resulta no igual dever de defender esse direito. O direito, nesse contexto, é observado paradoxalmente como a possibilidade da moral e, justamente por isso, a possibilidade da imoralidade. Isso significa que o direito inicialmente se aloca ao lado da moral, mas não se confunde com ela, todavia, posteriormente, torna-se o meio necessário para a realização de determinados valores morais. ${ }^{23}$

\section{DIFERENCIAÇÃO FUNCIONAL E COMUNICAÇÃO MORAL EM LUHMANN}

Toda a discussão sobre um pretenso fundamento moral para o direito, contudo, esbarra na teoria dos sistemas sociais autopoiética proposta por Niklas Luhmann.

20 RADBRUCH, Gustav. Filosofia do direito. Coimbra: Armênio Amado Editor, 1974. p. 103-104.

21 RADBRUCH, Gustav. Filosofia do direito. Coimbra: Armênio Amado Editor, 1974. p. 111.

22 A ideia de autonomia em Kant relaciona-se fundamentalmente com o reconhecimento de uma natureza humana que subjaz a diversidade de comportamentos e leis. Kant observa a necessidade de sujeição do homem à lei moral, sendo que essa lei moral possibilita que o indivíduo se torne livre justamente em razão de submeter-se à sua própria lei. Em outras palavras, o princípio kantiano da autonomia permite que as ações humanas sejam guiadas pela própria vontade humana, caracterizando a possibilidade de autolegislação. Isso é traduzido pelo imperativo categórico: "age apenas segundo uma máxima tal que possas ao mesmo tempo querer que ela se torne lei universal". Vide KANT, Immanuel. Fundamentação da metafísica dos costumes. Lisboa: Edições 70, 1988. p. 59. 
Para Luhmann, o direito não pode ser fundamentado pela moral, eis que a autonomia possibilitada pela continuidade das operações autopoiéticas do direito não permite qualquer fundamento externo. Isso significa que comunicações, ao alcançarem determinados níveis de recursividade na sociedade, especificam-se de tal modo que se tornam capazes de delimitar seus próprios pressupostos operativos.

Os sistemas sociais operam em condições de clausura operativa, negandose a possibilidade de validade direta da moral no interior do sistema jurídico. ${ }^{24} \mathrm{Da}$ especificação do sistema como unidade, o direito apenas é válido como direito, bem como a moral apenas é válida como moral. Em outras palavras, o fechamento operativo do sistema jurídico não permite que a moral delimite diretamente o conteúdo do direito, muito embora sejam possíveis formas específicas de interrelações entre esses dois âmbitos comunicativos.

Luhmann aponta a diferença entre autorreferência e heterorreferência, ou, entre clausura e abertura. Essa distinção aponta para a possibilidade de que o direito enlace comunicações jurídicas com comunicações jurídicas, viabilizando sua especificação como unidade. Já sua programação determina quais são aquelas situações nas quais o direito deve operar de forma cognitiva. Dito de outro modo, a comunicação jurídica torna-se capaz de especificar seus pressupostos operativos, distinguindo-se de seu ambiente por meio de um código próprio (direito/não direito), bem como estabelecendo programas capazes de delimitar formas específicas de abertura para comunicações que não se identificam imediatamente com o código jurídico.

A clausura operacional do direito em momento algum nega a importância do entorno. Paradoxalmente, a abertura do direito apenas é possível por meio de seu fechamento. Nesse aspecto, Luhmann não nega a importância da moral ou sua utilização pelo direito, mas questiona simplesmente a busca de um fundamento moral para o sistema jurídico, salientando que a tese do fechamento operativo dos sistemas autopoiéticos assume justamente uma posição contrária à possibilidade de validade imediata da moral autônoma no campo do direito.

O fechamento operativo, ainda, pressupõe a contínua auto-observação do sistema mediante sua codificação específica (direito/não direito). A abertura cognitiva, dessa maneira, será viabilizada justamente pelos critérios de fechamento

\footnotetext{
24 LUHMANN, Niklas. El derecho de la sociedad. 2. ed. México: Herder/Universidad Iberoamericana, 2005. p. 134.
} 
do sistema jurídico. Nesse aspecto, a abertura sistêmica sempre ocorre mediante a necessidade de integrar o caso particular à prática jurídica presente. A moral apenas adquire qualquer relevância jurídica quando internalizada pelo próprio direito ${ }^{25}$, momento em que não mais se pode falar em moral, mas sim em direito.

Evidentemente Luhmann não pretende um sistema jurídico incapaz de observar critérios morais, mas tão somente afasta o caráter de fundamento moral do direito. A moral, contudo, não se caracteriza como um sistema funcional autônomo, mas sim como um fenômeno difuso capaz de operar diante dos mais diversos âmbitos da sociedade funcionalmente diferenciada. ${ }^{26}$

A moral não se confunde com a atribuição de critérios normativos, tal como o direito, mas observa a realidade social desde uma amplitude de perspectivas. Ao operar mediante a distinção direito/não direito, o sistema jurídico exclui possibilidades que não se identifiquem com tal binariedade. Já a moral, por sua vez, relacionase com formas de observação que dizem respeito à adequação de determinadas condutas com base na distinção entre apreço ou desprezo pelos indivíduos.

Ainda com outras palavras, Luhmann pugna por uma constante possibilidade de aprendizado recíproco entre sistemas autônomos, o que assegura a liberdade de desenvolvimento de racionalidades comunicativas diversas, sem que ocorram processos alopoiéticos. ${ }^{27} \mathrm{~A}$ moral, nesse contexto, é observada pelo direito na forma de acoplamentos, perturbações ou irritações, assegurando-se ao sistema jurídico certa imunidade quanto a comandos morais diretos.

Nesse contexto, exclui-se uma observação da moral como um supercódigo metarregulador de outros sistemas sociais. ${ }^{28}$ É precisamente por essa incapacidade

25 A esse respeito, ainda que com critérios teóricos e metodológicos diversos, é de ser mencionada a igual autonomização entre direito e moral realizada por Habermas. Para o herdeiro intelectual da Escola de Frankfurt, a relação entre direito e moral não aponta para uma neutralidade da moral em relação ao direito, mas evidencia um trânsito de elementos morais via processo legislativo para o interior do direito. A relação de complementariedade entre direito e moral aponta para a co-originariedade entre tais âmbitos normativos, isto é, preceitos morais ingressam na ordem jurídica no momento da promulgação de determinada lei. O legislador internaliza preceitos morais quando os considera para a proposição de determinado comando jurídico-normativo. Isso significa que os preceitos morais ingressam no direito, porém, no momento em que passam a integrar a norma jurídica, não se pode mais falar em moral (tampouco em fundamento moral), mas tão somente em direito. HABERMAS, Jürgen. Direito e democracia: entre facticidade e validade. v. I. Rio de Janeiro: Tempo Brasileiro, 2003. p. 144.

26 CORSI, Giancarlo; ESPOSITO, Elena; BARALDI, Cláudio. Glosario sobre la teoría social de Niklas Luhmann. Barcelona: Antrophos, 1996. p. 154.

27 Conforme expressão utilizada por NEVES, Marcelo. Transconstitucionalismo. São Paulo: Martins Fontes, 2009. p. 44.

28 LUHMANN, Niklas. La sociedad de la sociedad. Ciudad de México: Universidad Iberoamericana/Herder Editorial, 2007. p. 826. 
funcional de apresentar-se como fundamento, que o sistema da moral torna-se capaz de observar problemas difusos. ${ }^{29}$ Isso significa que, ao deslocar-se a moral do status de fundamento para o de observadora concorrente - ou de observadora de segunda ordem ${ }^{30}$-, os problemas de corrupção sistêmica e sabotagens de código tornam-se observáveis moralmente.

A moral, portanto, não é capaz de fundamentar os sistemas sociais, eis que a especificidade de seu código não se amolda à binariedade da codificação de outros sistemas. A decisão jurídica não pode ser boa ou má, mas simplesmente conforme o direito ou desconforme o direito. ${ }^{31}$ Da mesma maneira, a economia se ocupa com a adequação ao ganho ou à perda, não havendo qualquer juízo moral economicamente realizado sobre a decisão econômica.

Essa constatação, de forma alguma, nega ou exclui a comunicação moral, mas somente realoca a moralidade social em um âmbito difuso. A moral, que até o século XVIII permanecia agrilhoada ao status de fundamento da sociedade, libertase para assumir uma função primordial junto aos processos de diferenciação social e, em última análise, ao assumir uma função de alarme, contribui para a continuidade das operações sociais. ${ }^{32}$

O sistema social conta com a moral como uma segurança contra processos de desdiferenciação. "Se trata de la posibilidad de una existencia moral (= social) y no todavía - como en el siglo XVIII tardío - de una fundamentación de los juicios específicamente morales". ${ }^{33}$ Essa constatação implica o reconhecimento de que a moral opera essencialmente como um elemento social. Apenas se pode falar em moral como uma forma específica de comunicação capaz de permear toda a sociedade. ${ }^{34}$

29 NEVES, Marcelo. Transconstitucionalismo. São Paulo: Martins Fontes, 2009. p. 43-44.

30 LUHMANN, Niklas. ¿Cómo se pueden observar estructuras latentes? In: WATZLAWICK, Paul; KRIEG, Peter. EI ojo del observador: contribuciones al constructivismo. Barcelona: Gedisa, 1998. p. 63.

31 CORSI, Giancarlo; ESPOSITO, Elena; BARALDI, Cláudio. Glosario sobre la teoría social de Niklas Luhmann. Barcelona: Antrophos, 1996. p. 154.

32 LUHMANN, La sociedad de la sociedad. p. 316.

33 LUHMANN, La sociedad de la sociedad. p. 822.

34 Nesse contexto, "la moral ahora se reclama como 'autolimitación de lo social por lo social' y se equipa con seudónimos como los de naturaleza o razón. Nuevas exigencias 'éticas' trascienden las fronteras de las unidades familiares, tribales y locales, que únicamente habían conocido vínculos morales internos. Quienes participan en la comunicación se enfrentan más y más a la necesidad - sobre todo como lectores aunque también en un sinnúmero de interacciones, estando de viaje, por ejemplo - de adaptarse a gente desconocida, cuyos vínculos sociales no conocen ni pueden adivinar. La sociedad reacciona a esto con la generalización y universalización de las exigencias morales. Innumerables textos - aunque también clubes y círculos de discusión - sirven para asegurar esta nueva 
Ao concentrar sua atenção nas patologias sociais, a moral não se confunde com um pretenso fundamento para o direito ou para a sociedade latu sensu, mas, antes, afirma-se como uma forma comunicativa capaz de observar corrupções sistêmicas (jurídicas, políticas, econômicas, etc.) em um primeiro momento e, com isso, reconstruir moralmente respostas (morais) para, em um segundo momento, tornar-se capaz de estabelecer diálogos com outros discursos sociais. A moral, pois, adaptase à policontexturalidade que caracteriza a sociedade funcionalmente diferenciada, disponibilizando seu código (critérios morais) para outras operações sociais. ${ }^{35}$

Exemplificativamente, problemas de corrupção de códigos sistêmicos tornam-se problemas morais. Isso pode ser observado em casos, por exemplo, da sobreposição do sistema econômico sobre o direito nos casos de vendas de sentenças. Ainda, da religião sobre a política, nos casos em que orientações religiosas orientem decisões administrativas e assim por diante. A moral atua como uma eficaz solução para problemas sociais graves, cuja operacionalidade dos sistemas funcionais - seja em razão da corrupção sistêmica, seja em razão da baixa complexidade estrutural - não consegue resolver. ${ }^{36}$

Para além do reconhecimento kelseniano quanto à existência de vários sistemas morais autônomos, a observação luhmanniana reconhece na moral uma forma comunicativa capaz de assegurar a continuidade de processos de diferenciação funcional, bem como com base em seu código (bom/mau), de realizar observações difusas diante do multiculturalismo (ou policontexturalidade) que caracteriza a sociedade contemporânea.

O deslocamento da moral do status de fundamento para o de observadora permite, com base em sua codificação própria, que as patologias sociais sejam observadas moralmente conforme determinados programas morais específicos. Nesse contexto, muito embora a moral, na ótica luhmanniana, não opere como elemento fundamental do direito, ela assume uma forma comunicativa universal ao especificar-se como unidade mediante a consideração da diferença entre apreço/desprezo, o que se dá pela formação de um código binário delimitado pela forma bom/mau. ${ }^{37}$

moral general 'patriótica' de todos los seres humanos. Se espera que las personas se identifiquen activamente con el lado bueno del esquema moral y que lo muestren." LUHMANN, La sociedad de la sociedad. p. 822.

35 LUHMANN, La sociedad de la sociedad. p. 826.

36 LUHMANN, La sociedad de la sociedad. p. 316.

37 LUHMANN, La sociedad de la sociedad. p. 310. 
A universalidade comunicativa dessa distinção permite que a comunicação moral se amolde aos mais diversos sistemas sociais, observando, desde uma perspectiva de um observador de segunda ordem, determinados problemas de corrupção de códigos de outros observadores. É possível observar moralmente observações jurídicas, bem como observar juridicamente observações morais. É precisamente essa capacidade sistêmica que conduz à contínua reconstrução entre os diversos discursos sociais.

Evidentemente a universalização do código moral não pressupõe a existência de uma única moralidade, mas sim reafirma a possibilidade de observações capazes de considerar a imensa pluralidade de discursos sociais e de culturas existentes. Ao se observar a realidade como multicultural, a própria noção de moralidade torna-se observável desde uma perspectiva da unidade da multiplicidade, ou seja, as particularidades locais são reconstruídas no âmbito de um sistema identificado mediante sua codificação específica.

Nesse sentido, "la moral misma no dispone de un tercer valor y por eso permite fluctuaciones importantes en el ámbito temático de las moralizaciones"38, sendo que, a partir de tais flutuações, as infrações hábeis à caracterização de circunstancias moralmente condenáveis tornam-se explicáveis mediante determinadas variações comunicativas delimitadas a partir de acoplamentos entre a comunicação moral e outras distinções - como o direito. Isso significa que o aquilo moralmente condenável sob determinados aspectos pode ser irrelevante sob outros.

\section{5. É POSSÍVEL UM FUNDAMENTO MORAL DO SISTEMA JURÍDICO?}

A reflexividade jurídica deve ser observada como intrinsecamente relacionada ao conceito de autonomia, o qual é bem definido por Teubner como a organização autorreferencial e autopoiética do sistema jurídico ${ }^{39}$. Construções lógico-formais baseadas em conceitos ${ }^{40}$,

38 LUHMANN, La sociedad de la sociedad. p. 311.

39 TEUBNER, Gunther. Autopoiesis in law and society: a rejoinder to Blankenburg. Law \& Society Review: Law and Society Association: Salt Lake City. v. 18, n. 2, 1984. p. 295: "To understand reflexive law, it is crucial to understand what is meant by autonomy. [...] By autonomy I mean the self-referential and autopoietic organization of the legal system."

40 LARENZ, Karl. Metodologia da ciência do direito. 4. ed. Lisboa: Fundação Calouste Gulbenkian, 2005. p. 
interesses ${ }^{41}$ ou valores ${ }^{42}$ são frontalmente dissonantes da realidade autorreferencial que embasa a metodologia por meio da qual se observa o Direito como sistema autopoiético. Para muito além de qualquer edificação lógico-formal ou arraigada em uma ordem hierárquico-verticalizada sustentada em um pretenso fundamento último do ordenamento jurídico - como o fizeram em relação àquela Puchta, Jhering, Heck e, a esta, Kelsen e Hart -, a perspectiva seguida distancia-se de lógicas unitárias ou tendentes a buscar fundamentos últimos, assentando-se em sua própria operacionalidade reflexiva.

Nota-se que a perspectiva kelseniana - então paradigma predominante no ensino e na prática jurídica brasileira - é enfraquecia a partir da capacidade reflexiva denunciada por Luhmann e, principalmente, Teubner. Se a ordem jurídica é autoconstruída a partir de uma referência unitária a si mesma, então nenhum fundamento de validade é possível. Amparado na teoria sistêmica de Luhmann, Teubner identificou esse problema quando observou os conhecidos paradoxos da autorreferência ${ }^{43}$, afirmando que uma distinção aplicada com pretensão de validade universal reconduz à própria distinção fundante, culminando no bloqueio do processo decisório em razão de uma impossibilidade lógica, imputável ao observador, em distinguir por si mesmo a unidade distintiva que lhe permite a observação.

Dito de outro modo, a pretensão de um fundamento racional último culmina na clássica pergunta sobre o fundamento do fundamento - ao qual Kelsen buscou solucionar pelo recurso à grundnorm enquanto base fundamental pressuposta no sistema. ${ }^{44}$ Ao contrário de Kelsen, Luhmann rechaça a ideia de fundamentos

25. KAUFMANN, Arthur; HASSEMER, Winfried (Org.). Introdução à filosofia do direito e à teoria do direito contemporâneas. Lisboa: Fundação Calouste Gulbenkian, 2002. p. 168. LOSANO, Mario Giuseppe. Sistema e estrutura no direito. Volume 1: Das origens à escola histórica. São Paulo: Martins Fontes, 2008. p. 338.

41 HECK, Philipp. El problema de la creación del derecho. Granada: Comares, 1999. p. 21; HECK, Philipp. Interpretação da lei e jurisprudência dos interesses. São Paulo: Saraiva, 1947. p. 5; CANARIS, Claus-Wilhelm. Pensamento sistemático e conceito de sistema na ciência do direito. Lisboa: Fundação Calouste Gulbenkian, 1996. p. 61.

42 LOSANO, Mario Giuseppe. Sistema e estrutura no direito. Volume 2: O século XX. São Paulo: Martins Fontes, 2010. p. 252; ALEXY, Robert. Direitos fundamentais, balanceamento e racionalidade. Ratio Juris. v. 16, n. 2 , jun. 2003. p. 134; CANARIS, Claus-Wilhelm. A influência dos direitos fundamentais sobre o direito privado na Alemanha. In: SARLET, Ingo Wolfgang. (Org.). Constituição, direitos fundamentais e direito privado. Porto Alegre: Livraria do Advogado, 2003. p. 228. Vide, ainda, a crítica de Streck à chamada jurisprudência dos valores em STRECK, Lenio Luiz. Verdade e consenso. 4. ed. São Paulo: Saraiva, 2011. p. 48;

43 TEUBNER, O direito como sistema autopoiético, 1989, p. 6-7: "sempre que a distinção é aplicada, não apenas casuisticamente, mas com pretensões de validade para todo um universo de situações, então mais tarde ou mais cedo, essa mesma pretensão de validade universal acabará por conduzir a própria distinção à tentação de valer igualmente para si mesma".

44 Cuja pressuposição Kelsen justifica pela impossibilidade lógica de se buscar o fundamento da norma mais elevada pelo recurso à legitimação de autoridades para sua elaboração, eis que tal legitimação necessariamente dependeria 
para os sistemas, entendendo que a tentativa de localizar fundamentos esbarra inevitavelmente em paradoxos capazes de bloquear o processo decisório, eis que "existem paradoxos em todos os lugares, sempre que procuramos por fundamentos" 45 últimos capazes de conferir validade ao Direito.

É exatamente o distanciamento para com fundamentos racionais - ou transcendentais - que aponta para a circularidade específica das operações levadas a efeito pelo sistema do Direito. Se a busca por um fundamento é uma busca inócua, então se pode perceber que tal status fundamental é transferido de uma ordem hierárquico-verticalizada para uma ordem circular-autorreferencial, na qual a validade relaciona-se com aqueles pressupostos racionais próprios à continuidade circular do sistema, ou seja, sua autopoiese.

Logo, exclui-se qualquer possibilidade de um fundamento último da ordem jurídica incluindo-se aqui a possibilidade de um fundamento de ordem moral. Essa realidade afirma aquilo que Hofstadter definiu como hierarquias entrelaçadas ${ }^{46}$, identificando que a questão da legitimidade ou fundamento em uma rede fechada impõe uma racionalidade reflexiva a partir da qual a norma de níveis mais elevado encontrará sua fonte de legitimação na norma de nível mais baixo ou, por assim dizer, no nível inviolável da circularidade. Tal construção é igualmente visível em Teubner, quando, amparado em Hofstadter, define a autopoiese do Direito exatamente a partir dessa perspectiva circular e permeada por paradoxos. ${ }^{47}$

Convém notar que tal ideia conduz ao reconhecimento quanto à existência de uma rede de comunicações jurídicas capazes de fazer referência a várias possibilidades de novas comunicações igualmente jurídicas. A validade da norma jurídica, em linhas gerais, aponta para a aceitação da comunicação jurídica pela própria comunicação jurídica, ou seja, é um símbolo próprio do sistema do Direito. Logo, tal símbolo não pode ser utilizado em nenhum outro lugar da sociedade, bem como não comporta a substituição por qualquer outra distinção que não a jurídica.

de outra norma jurídica. KELSEN, Hans. Teoria pura do direito. São Paulo: Martins Fontes, 2006. p. 217.

45 LUHMANN, Niklas. A terceira questão: o uso criativo dos paradoxos no Direito e na história do Direito. Estudos jurídicas, São Leopoldo, n. 32. jan./jun., 2006. p. 46. Vide igualmente MAGALHÃES, Juliana Neuenschwander. O uso criativo dos paradoxos do direito. In: ROCHA, Leonel Severo. Paradoxos da auto-observação: percursos da teoria jurídica contemporânea. Curitiba: JM, 1997. p. 248-249; ROCHA, Leonel Severo. Observações sobre a observação luhmanniana. In ROCHA, Leonel Severo, KING, Michael; SCHWARTZ, Germano. A verdade sobre a autopoiese no direito. Porto Alegre: Livraria do Advogado, 2009. p. 21-23.

46 HOFSTADTER, Douglas Richard. Gödel, Escher e Bach: um entrelaçamento de gênios brilhantes. Brasília: Universidade de Brasília, 2001. p. 761.

47 TEUBNER, Gunther. O direito como sistema autopoiético. Lisboa: Fundação Calouste Gulbenkian, 1989. p. 5-7. 
A teoria e a prática do direito constantemente enfrentam o problema da invasão da esfera jurídica por elementos morais. Os juízos valorativos eivados de elementos morais acabam por induzir o direito ao problema da desdiferenciação funcional, substituindo a lógica binária direito/não-direito pela distinção bom/ mau ou apreço/desapreço e, via de consequência, impulsionando o sistema a uma práxis que não lhe é própria e, tampouco, adequada.

Ao operar a partir de uma distinção fundamental que lhe caracteriza, o sistema jurídico deve manter-se fechado operativamente objetivando exatamente a proteção contra comunicações externas que tendem colonizá-lo. A comunicação moral é uma dessas formas comunicativas que, operando desde a perspectiva do apreço/desapreço, pode ser utilizada pelo sistema jurídico, desde que transformada em comunicação do sistema que a observa a partir da estratégia da dupla seletividade e da internalização de problemas.

A moral possui nítida relevância junto ao sistema jurídico, contudo, tal relevância aponta quando essa forma comunicativa for observada desde a perspectiva interna do próprio sistema, restando internalizada como comunicação passível de observação jurídica e, jamais, como elemento extrajurídico capaz de servir como elemento fundamental da funcionalidade do sistema do direito.

\section{REFERÊNCIAS DAS FONTES CITADAS}

CANARIS, Claus-Wilhelm. Pensamento sistemático e conceito de sistema na ciência do direito. Lisboa: Fundação Calouste Gulbenkian, 1996.

CORSI, Giancarlo; ESPOSITO, Elena; BARALDI, Cláudio. Glosario sobre la teoría social de Niklas Luhmann. Barcelona: Antrophos, 1996.

HABERMAS, Jürgen. Direito e democracia: entre facticidade e validade. v. I. Rio de Janeiro: Tempo Brasileiro, 2003.

HART, Herbert L. A. O conceito de direito. Lisboa: Fundação Calouste Gulbenkian, 1994.

HECK, Philipp. El problema de la creación del derecho. Granada: Comares, 1999. p. 21; HECK, Philipp. Interpretação da lei e jurisprudência dos interesses. São Paulo: Saraiva, 1947.

HOFSTADTER, Douglas Richard. Gödel, Escher e Bach: um entrelaçamento de gênios brilhantes. Brasília: Universidade de Brasília, 2001. 
KANT, Immanuel. Fundamentação da metafísica dos costumes. Lisboa: Edições 70, 1988.

KELSEN, Hans. Teoria pura do direito. 7. ed. São Paulo: Martins Fontes, 2006.

LARENZ, Karl. Metodologia da ciência do direito. 4. ed. Lisboa: Fundação Calouste Gulbenkian, 2005. p. 25. KAUFMANN, Arthur; HASSEMER, Winfried (Org.). Introdução à filosofia do direito e à teoria do direito contemporâneas. Lisboa: Fundação Calouste Gulbenkian, 2002.

LOSANO, Mario Giuseppe. Sistema e estrutura no direito. Volume 1: Das origens à escola histórica. São Paulo: Martins Fontes, 2008.

LOSANO, Mario Giuseppe. Sistema e estrutura no direito. Volume 2: O século XX. São Paulo: Martins Fontes, 2010.

LUHMANN, Niklas. A terceira questão: o uso criativo dos paradoxos no Direito e na história do Direito. Estudos jurídicas, São Leopoldo, n. 32. jan./jun., 2006.

LUHMANN, Niklas. ¿Cómo se pueden observar estructuras latentes? In: WATZLAWICK, Paul; KRIEG, Peter. El ojo del observador: contribuciones al constructivismo. Barcelona: Gedisa, 1998.

LUHMANN, Niklas. El derecho dela sociedad.2.ed. México:Herder/Universidad Iberoamericana, 2005.

LUHMANN, Niklas. La sociedad de la sociedad. Ciudad de México: Universidad Iberoamericana/ Herder Editorial, 2007.

MAGALHÃES, Juliana Neuenschwander. O uso criativo dos paradoxos do direito. In: ROCHA, Leonel Severo. Paradoxos da auto-observação: percursos da teoria jurídica contemporânea. Curitiba: JM, 1997.

RADBRUCH, Gustav. Filosofia do direito. Coimbra: Armênio Amado Editor, 1974.

ROCHA, Leonel Severo. Observações sobre a observação luhmanniana. In ROCHA, Leonel Severo, KING, Michael; SCHWARTZ, Germano. A verdade sobre a autopoiese no direito. Porto Alegre: Livraria do Advogado, 2009.

TEUBNER, Gunther. Autopoiesis in law and society: a rejoinder to Blankenburg. Law \& Society Review: Law and Society Association: Salt Lake City. v. 18, n. 2, 1984.

TEUBNER, Gunther. O direito como sistema autopoiético. Lisboa: Fundação Calouste Gulbenkian, 1989.

Recebido em: junho/2018

Aprovado em: agosto/2018 